\title{
ТЕРМИЧЕСКИ И ОПТИЧЕСКИ СТИМУЛИРОВАННЫЕ ЯВЛЕНИЯ В МОНОКРИСТАЛЛАХ СУЛЬФИДА КАДМИЯ
}

Одновременное изучение люминесценции и фотопроводимости твердых тел перспективно ввиду возможности получения более полной информации о механизме этих явлений. $\mathrm{K}$ настоящему времени имеется уже целый ряд работ по параллельному изучению, люминесценции и фотопроводимости сульфида кадмия (см., напр., $\left[{ }^{1-6}\right]$ ).

В данной работе исследованы термовысвечивание, термостимулированный ток, оптическая вспышка и оптическое тушение фотопроводимости и люминесценции ряда: монокристаллов CdS.

\section{Методика}

Монокристаллы CdS выращивались из паровой фазы методом возгонки в потоке аргона. Исходный материал - сульфид кадмия марок «для полупроводников» и «для люминофоров». Первый из них по данным спектрального анализа содержал серебро в: концентрации $3 \cdot 10^{-5}$ 2/2, во второй серебро вводилось при выращивании. В излучении полученных кристаллов наряду с зеленым краевым излучением проявлялись более или менее интенсивные полосы, характерные для серебра.

Галлиевые контакты наносились на кристаллы методом наплавления. В случае низкотемпературных измерений кристаллы, закрепленные на медном блоке, покещались непосредственно в стеклянный сосуд Дьюара с жидким азотом. Спектры свєчения снимались с помощью монохроматора УМ-2, фотоэлектронного умножителя ФЭУ-27 и узкополосного усилителя (излучение модулировалось). Возбуждение производилось ртутной линией 365 нм. Спектры оптической вспышки и термовысвечивания снимались путем неоднократного воспроизведения этих явлений и регистрации интенсивности возникающего свечения через монохроматор, настроенный на ту или иную длину волны.

Токи через кристалл измерялись с помощью электрометрического усилителя. Скорость нагрева при съемке кривых термовысвечивания и термостимулированного тока составляла 0,3 град/сек.

Спектры стимуляции оптической вспышки и тушения фотопроводимости снимались с помощью монохроматора SPM-1 и лампы накаливания. При этом интенсиьность вспышки регистрировалась через другой монохроматор.

\section{Результаты экспериментов}

По спектрам излучения при $77^{\circ} \mathrm{K}$ исследованные кристаллы могут быть разделены на следующие три группы:

I. Кристаллы с интенсивным краевым излучением и относительно слабым длинноволновым излучением в области красной и оранжевой полос $(156,209,212,214)$. 
II. Кристаллы с оранжевым излучением $(223,225,226)$.

III. Кристаллы со сравнимыми зеленой, оранжевой и красной полосами излучения $(231,243,246)$.

При комнатной температуре у кристаллов II и III групп наблюдается красное излучение. Типичные спектры свечения приведены на рис. 1.

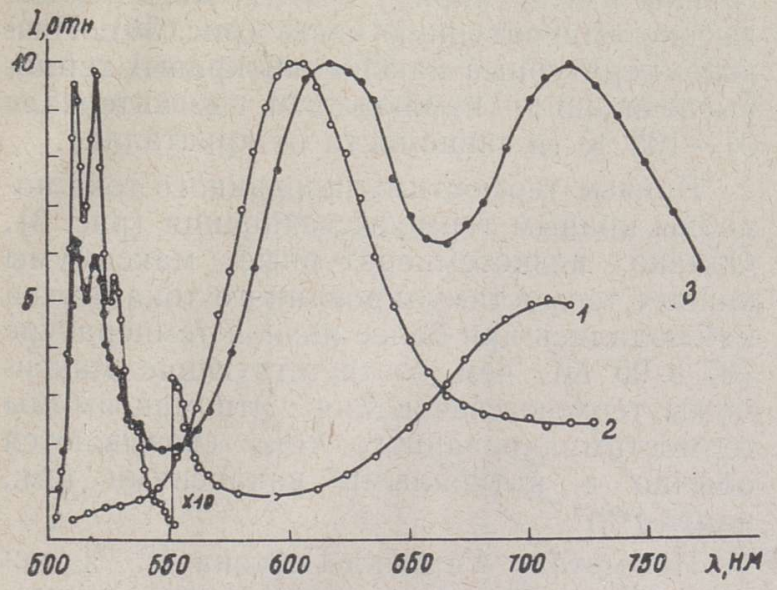

Рис. 1. Спектры излучения кристаллов $\mathrm{CdS}$ при $77^{\circ} \mathrm{K}: 1-156 ; 2-223 ; 3-246$

Температурные зависимости полос излучения и фотопроводимости типичных представителей этих групп представлены на рис. 2. Зеленое излучение практически полностью тушится уже при $125^{\circ} \mathrm{K}$ (I и III группы). Рассчитанная по экспериментальным данным энергия активации температурного тушения $E_{\mathrm{a}}=0,11 \div 0,12$ эв согласуется с литературными данными $\left[{ }^{7-9}\right]$.

Интенсивность оранжевой полосы обычно имеет максимум в пределах температур 140 -

$170^{\circ} \mathrm{K}$. У кристаллов III группы ввиду перекрытия полос такой ход температурной зависимости может искажаться. Из кривых температурного тушения оранжевой полосы была найдена энергия активации $E_{\mathrm{a}}=0,2 \div 0,3$ эв . Температурная зависимость красной полосы довольно сильно варьируется от кристалла к кристаллу.

C повышением температуры у кристаллов I группы наблюдается резкое уменьшение фототока в той же области температур, где уменьшается интенсивность зеленого свечения. У кристаллов II и III групп такой резкой зависимости не наблюдается.

Рис. 2. Температурные зависимости фототока и полос излучения кристаллов $156(a), 226$ (б), $246(в): 1 a, 16,18-$ фототока; $2 a, 2 \beta$ - красной полосы; $2 \sigma, 38-$ оранжевой полосы; $3 a-$ зеленого краевого излучения.

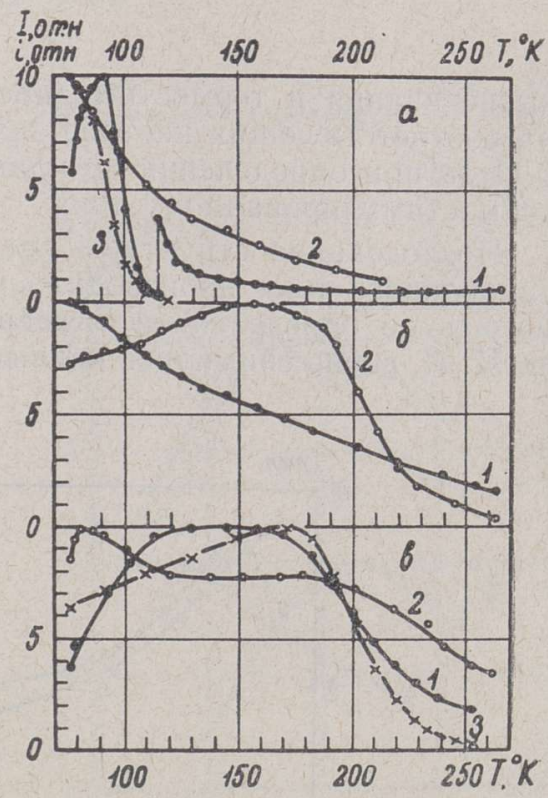

* В предположении, что температурное тушение описывается формулой $I=$ $=I_{0}\left(1+A e^{\left.-\frac{E_{\mathrm{a}}}{K T}\right)^{-1}}\right.$. 
Термовысвечивание обнаружено у всех исследованных кристаллов $\mathrm{CdS}$. Однако у некоторых кристаллов, особенно II группы, оно настолько слабо, что его детальное исследование оказалось невозможным. Кристаллы I группы имеют только низкотемпературный максимум тер-

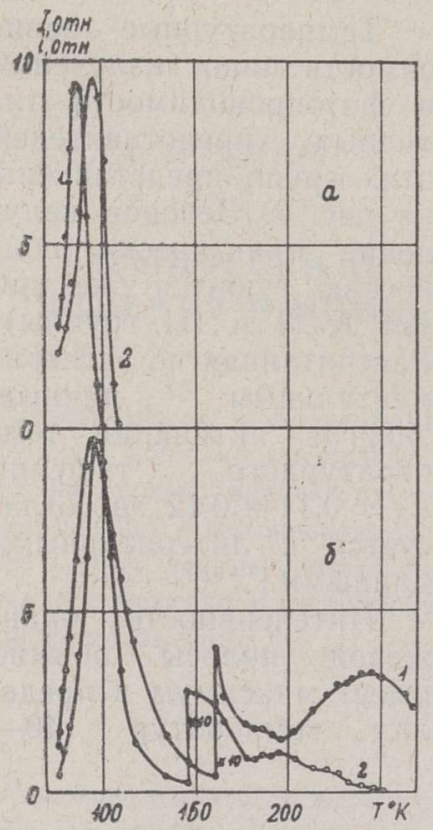
мовысвечивания (рис. $3 a$ ). В отличие от них кривые термовысвечивания кристаллов III группы имели наряду с этим максимумом высокотемпературную часть (рис. 3б). Низкотемпературные максимумы кривых термовысвечивания наблюдались в интервале $91-103^{\circ} \mathrm{K}$ (в зависмости от кристалла).

Кривые термостимулированного тока подобны кривым термовысвечивания (рис. 3). Однако низкотемпературные максимумы кривых термостимулированного тока всегда наблюдались при более низкой температуре $\left(87 \div 95^{\circ} \mathrm{K}\right)$, чем соответствующие максимумы термовысвечивания. Эти максимумы термостимулированного тока связываются обычно с катионными вакансиями (см., напр., $\left.\left[{ }^{10}\right]\right)$.

По методу Гарлика-Гибсона $[11,12]$, используя возрастающие ветви кривых термо-

Рис. 3. Кривые термостимулированного тока (1) и термовысвечивания (2) кристаллов: $a-156 ; \sigma-243$.

высвечивания и термостимулированного тока, была определена глубина соответствующих центров захвата. Она оказалась в среднем равной 0,11 эв при определении по кривым термовысвечивания и 0,09 эв - по термостимулированному току.

Исследование структуры кривых термовысвечивания и термостимулированного тока производилось по следующей методике: кривые снимались до определенной температуры, кристалл повторно охлаждался до $77^{\circ} \mathrm{K}$, вновь снимались кривые и т. д. В результате было установлено,



Рис. 4. Спектры ИК тушения фототока (1) и стимуляции оптической вспышки (2) кристалла 246. 
что уровни захвата в кристаллах первой группы элементарны и вероятность повторных захватов на них мала (см., напр., $\left.\left[{ }^{13}\right]\right)$. Картина, полученная в случае кристаллов III группы, указывает на существование уровней захвата различной глубины.

Оптическая вспышка наблюдалась у кристаллов I и III групп и у кристалла II группы, в спектре которого имелась слабая красная полоса. Спектры стимуляции оптической вспышки исследованных кристаллов повторяют спектры ИК тушения фототока (рис. 4). Последние определялись по влиянию ИК света на релаксацию фотопроводимости. Оптическая вспышка сопровождается тушением фотопроводимости (рис. 5).



Рис. 5. Кривые тушения фототока (1) и оптической вспышки (2) кристалла 243; 3 и 4 - ход кривых без

ИК света соответственно.

В спектрах оптической вспышки преобладает оранжевая полоса, хотя у некоторых кристаллов присутствует и красный компонент (рис. 6). В спектрах термовысвечивания наблюдаются как красные, так и оранжевые полосы. Однако имеются кристаллы (напр., 246), у которых, несмотря на наличие оранжевой полосы в спектре излучения, термовысвечивание красное (рис. 6). Оптическая вспышка наблюдалась нами и при стационарном возбуждении.

При облучении кристаллов ИК светом в области $800-1700 \mathrm{H \mu}$ во время стационарного возбуждения было обнаружено ИК тушение красной полосы излучения, которое может достигать $40 \%$.

Рис. 6. Спектры оптической вспышки (I) и термовысвечивания (2) для кристаллов: $a-246 ; \sigma-243 ; в-156$.






\section{Обсуждение результатов}

Рассмотрение результатов, полученных при изучении температурной зависимости люминесценции и фотопроводимости кристаллов I группы, в спектрах излучения которых доминирует зеленая полоса, показывает, что зеленое излучение и фототок тушатся в одной и той же довольно узкой температурной области. Наблюдающееся у некоторых кристаллов возрастание фототока около $77^{\circ} \mathrm{K}$, возможно, связано с освобождением электронов с центров захвата. Резкое уменьшение интенсивности свечения и фотопроводимости при повышении температуры можно объяснить, если считать, что зеленое излучение возникает при рекомбинации свободного электрона с дырками, локализованными на уровнях вблизи валентной зоны $[2,7,14]$. Термическое освобождение дырок приводит к тушению зеленого краевого излучения и фотопроводимости.

Ход кривых термовысвечивания в общих чертах повторяет ход кривых термостимулированного тока (кристаллы I и III групп). Это говорит о том, что оба явления, по-видимому, связаны с освобождением носителей тока с одних и тех же центров захвата. Следует отметить, что температурное тушение может сильно искажать кривые термовысвечивания и термостимулированного тока (см., напр., $\left.\left[{ }^{15}\right]\right)$. Этим, по-видимому, объясняется тот факт, что низкотемпературный максимум термостимулированного тока сдвинут в низкотемпературную сторону по отношению к максимуму термовысвечивания, хотя по теоретическим соображениям следовало бы ожидать обратного [16].

В плохо проводящих полупроводниках, каким является и $\mathrm{CdS}$, знак термостимулированного тока должен, как правило, совпадать со знаком равновесной проводимости $\left[{ }^{10,17}\right]$. Так как $\mathrm{CdS}$ обладает электронной проводимостью $\left[{ }^{18,19}\right]$, то на основании наших данных можно думать, что термовысвечивание, как іл термостимулированный ток, обусловлено освобождением электронов с центров захвата.

Оптическая вспышка и ИК тушєние проводимости в предварительно возбужденных кристаллах CdS-Ag исследовались в работах Ламбе и Клика $[5,6]$. Считается, что ИК тушение фотопроводимости связано с освобождением дырок с центров чувствительности [20]. Из наших данных следует, что спектр стимуляции вспышки совпадает со спектром тушения фотопроводимости. При этом оптическая вспышка в исследованных кристаллах не сопровождается вспышкой проводимости. Это свидетельствует, по-видимому, о том, что оптическая вспышка связана с освобождением дырок с локальных уровней в запрещенной зоне.

У ряда исследованных кристаллов спектры оптической вспышки не совпадают со спектрами термовысвечивания. Преимущественно оранжевый цвет вспышки говорит о том, что рекомбинация освобождаемых ИК светом дырок с электронами происходит главным образом на оранжевых центрах. Различие спектров термовысвечивания и оптической вспышки можно связать с тем, что первое явление имеет электронный, а второе - дырочный знак.

Инфракрасное тушение красной полосы излучения, по-видимому, связано с ИК тушением фотопроводимости, т. е. с освобождением дырок с центров чувствительности. Не исключено, что ИК свет освобождает дырки и непосредственно с центров красного свечения. В связи с этим интересно отметить, что оптическая вспышка наблюдалась нами лишь у кристаллов, обладающих по крайней мере слабой красной полосой излучения.

Подводя итог, мы считаем, что люминесценция сульфида кадмия может, по-видимому, возникать как при освобождении электронов, так 
и дырок с соответствующих центров захвата. Обсуждение детального механизма свечения нам кажется пока что преждевременным.

Авторы выражают искреннюю благодарность А. Рууту за выращивание монокристаллов.

\section{Л И ТЕ Р А Т У Р А}

1. Broser I., W a r m insky R., Z. Phys., 133, 340 (1952)

2. Broser I., Broser-Warminsky R., Klipping G., Ross R., Schulz H.-J., J. Phys. Chem. Solids, 22, 213 (1961).

3. Lambe J. J., K1 ick C. C., Dexter D. L., Phys. Rev., 103, 1715 (1956).

4. L a m b e J. J., Phys. Rev., 98, 985 (1955).

5. L a m b e J. J., Phys. Rev., 100, 1586 (1955).

6. L a m b e J. J., K li ck C. C., Phys. Rev., 98, 909 (1955).

7. S p e a r W. E., B r a d berry G. W., Phys. stat. sol., 8, 649 (1965).

8. Р а 3 би ри и Б. С., ФТТ, 6, 318 (1964).

9. S e iwe rt R., Abh. Dtsch. Akad. Wiss. Berlin, K1. Math. Phys, u. Techn., Nr. 7, $84(1960)$.

10: $\mathrm{S}$ k a r m a n J. S., Solid-State Electronics, 8, 17 (1965).

11. H a a ke C. H., J. Opt. Soc. Am., 47, 649 (1957).

12. Nicholas K. H., Woods J., Brit. J. Appl. Phys., 15, 783 (1964).

13. Л ущ и к Ч. Б., Тр. Ин-та физ. и астрон. АН ЭССР, № 3,35 (1955).

14. Coll in s R. J., J. Appl. Phys., 30, 1135 (1959).

15. Л у и к Ч. Б., Тр. Ин-та физ. и астрон. АН ЭССР, № 3, 64 (1955).

16. П ург а А. П., Р е бан е К. К., Тр. Ин-та физ. и астрон. АН ЭССР, № 15,149 (1961).

17. Рывкин С. М., Фотоэлектрические явления в полупроводниках, M., 1963 , cтр. 282.

18. K röger F. A., Vink H. J., Volg e r J., Philips Res. Rep., 10, 39 (1955).

19. Kröger F. A., Vink H. J., J. van den B o o m ga a rd, Z. Phys. Chem., 203, 1 (1954).

20. Bube R. H., Photoconductivity of Solids, N. Y. - London, 1960.

Ннститут физики и астрономии

Академии наук Эстонской ССР

Поступила в редакцию 24/XI 1965

\section{A. AIDLA, J. KIRS}

\section{TERMILISELT JA OPTILISELT STIMULEERITUD NÄHTUSED CdS MONOKRISTALLIDES}

Hõbeda lisandiga CdS monokristallidel uuriti termostimuleeritud juhtivust, termoväljakiiritamist, optilist sähvatust, juhtivuse infrapunast kastutamist, fotoluminestsentsi ja fotojuhtivuse temperatuurilist sõltuvust. Saadud tulemuste pöhjal tehakse järeldus, et luminestsents CdS kristallides võib tekkida nii elektronide kui ka aukude vabastamisel vastavatelt haardetsentritelt.

A. AIDLA, J. KIRS

\section{THERMALLY AND OPTICALLY STIMULATED PHENOMENA IN SINGLE CRYSTALS OF CADMIUM SULPHIDE}

Conductivity and luminescence glow curves, infrared stimulation of luminescence and quenching of conductivity, temperature dependence on photoluminescence and photoconductivity have been studied in single crystals of CdS with silver activator. From the results it is concluded that luminescence in CdS crystals may arise from the release of both trapped electrons and holes. 